\title{
Article \\ Method of Medical Equipment Evaluation and Preparation for On-Demand Additive Manufacturing with the Conventional Supply Chain Being Broken: A Case Study of Mask Filter Adapter Production during COVID-19
}

\author{
Michał Karoluk*(D), Gustaw Koenig (D) and Tomasz Kurzynowski (D) \\ Centre for Advanced Manufacturing Technologies (CAMT/FPC), Faculty of Mechanical Engineering, \\ Wroclaw University of Science and Technology, 50-371 Wroclaw, Poland; gustaw.koenig@pwr.edu.pl (G.K.); \\ tomasz.kurzynowski@pwr.edu.pl (T.K.) \\ * Correspondence: michal.karoluk@pwr.edu.pl
}

Citation: Karoluk, M.; Koenig, G.; Kurzynowski, T. Method of Medical Equipment Evaluation and Preparation for On-Demand Additive Manufacturing with the Conventional Supply Chain Being Broken: A Case Study of Mask Filter Adapter Production during COVID-19. Appl. Sci. 2021, 11, 12016. https://doi.org/10.3390/ app112412016

Academic Editor: Michal Puškár

Received: 22 November 2021 Accepted: 3 December 2021 Published: 17 December 2021

Publisher's Note: MDPI stays neutral with regard to jurisdictional claims in published maps and institutional affiliations.

Copyright: (c) 2021 by the authors. Licensee MDPI, Basel, Switzerland. This article is an open access article distributed under the terms and conditions of the Creative Commons Attribution (CC BY) license (https:/ / creativecommons.org/licenses/by/ $4.0 /)$.

\begin{abstract}
A year after the first cases, the COVID-19 pandemic continued to put immense pressure on healthcare systems worldwide. With supply chains broken, the only opportunity for hospitals was to turn to unconventional solutions to overcome medical equipment shortages in the shortest possible time. This paper describes the methodology that allows the preparation of medical equipment to be additionally manufactured in keeping with medical requirements. The proposed method focuses on cytotoxicity tests against HaCaT, L929, A549 cell lines, and the assessment of potential antimicrobial properties of materials. The application of the proposed method is shown by the example of an adapter that connects a full mask with widely available DAR filters. The prototyping and fabrication of adapters were conducted with the fused deposition modelling (FDM) and selective laser sintering (SLS) technologies. The adapters increased the number of masks available to medical personnel, and by the same token, ensured the continuity of their work.
\end{abstract}

Keywords: COVID-19; additive manufacturing; mask filter adapter; SLS technology; FDM technology

\section{Introduction}

In November 2019, a new disease was diagnosed in Wuhan City, Hubei Province, China that gave rise to severe pneumonia with flu-like symptoms. The disease was called COVID-19 due to the fact that it was caused by the SARS-CoV-2 coronavirus [1,2]. The coronavirus led to a pandemic, with approximately 242 million cases and almost 5 million deaths reported worldwide [1].

The SARS-CoV-2 coronavirus is transmitted mainly by airborne droplets through close physical contact [1-3]. The WHO called for the application of preventive measures, such as disinfection, distancing, and the appropriate use of personal protective equipment (PPE) $[1,4]$.

Recently, a large amount has been written regarding the manufacturing of masks, helmets, adapters, swabs, and respiratory by means of AM technology [5-9]. It has been found that AM methods can be a suitable tool for the further development and production of PPE, and that in the event of supply shortages, additive manufacturing can be rapidly applied. Still, more research is required regarding design procedures, suitable materials, sterilization, etc.

At the start of the pandemic, the personal protective equipment, especially mask filters, used by medical staff in emergency wards, was virtually unavailable in Poland and around the world $[10,11]$.

The available publications offer examples on the use of additive technologies. However, these are mainly examples of producing a single adapter for the full-face snorkel mask, with the FDM/FFF technology. In our work, we wanted to focus on presenting the method 
developed for on-demand additive manufacturing of spare parts and consumables for medical equipment, as well as personal protective equipment in a dispersed environment during crisis situations. This includes the case study of producing an adapter that allows the connection of a filter to the Honeywell North Pano CL3 full-face mask. The use of the methodology enables the selection of the best-suited AM technology and material for the application. The case includes the demand made by a hospital, upon which a prototype was made with the fused deposition modelling technology from the ABS material, and finally, a series of 150 adapters was produced using the selective laser melting (SLS) technology from the PA12 material. The adapters were used to equip all of the employees of a local COVID ward. This made it possible to multiply the number of masks available. Particularly, in a crisis, it helped maintain the continuity of medical staff work. In addition, the article presents the results of research into the cytotoxicity of the samples tested against $\mathrm{HaCaT}, \mathrm{L} 929, \mathrm{~A} 549$ cell lines, and antibacterial properties through the assessment of the surface colonisation capacity by microorganisms in tryptic soy broth (TSB) and in artificial saliva (AS).

\section{Materials and Methods}

To create the AM Virtual Storage or a digital parts repository, a method was developed for the adaption of medical equipment to additive manufacturing in the event of its inaccessibility as a result of a crisis. At each stage of the method, it is important to define the characteristics of the part, the proposed manufacturing method, and materials in the following areas (Figure 1):

- Usability;

- Manufacturing;

- Economic/environmental.

\section{Usability}

- ergonomics

- functionality

- sterilization

- life cycle

- cytotoxicity

- antibacterial

\section{Economic / environmental}

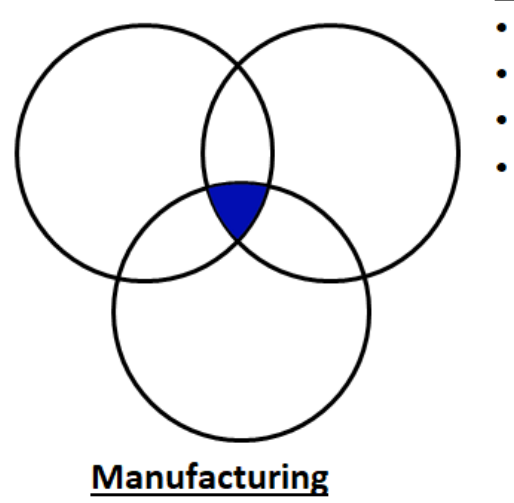

price of the material material availability availability of machines demand

Figure 1. Area and criteria for the selection of technology and materials.

Regarding the operational criteria, the shape of a part is defined by specifying its function and ergonomics, including its mass. The medical equipment must meet the requirements of cytotoxicity and antibacterial properties. The product needs to be identified for its usability-one-time or repeated-and sterility.

Economic and environmental criteria include the current price and availability of materials of which the part will be produced. In addition, it is crucial to determine the availability of the means of production under given conditions, and the machine costs of manufacturing. Moreover, the current and future demand should be determined.

Manufacturing criteria include the ability of a given manufacturing method to shape the part with a given roughness, porosity, and strength. These factors constitute the input data for the design for additive manufacturing (DfAM). Production capacity, which is 
understood as the efficiency of a single machine, should be taken into account. The last aspect is the scalability of the method, understood as the potential to increase production efficiency by increasing the number of machines or dispersing production among many market entities, such as service bureaus.

The method described here offers a solution that meets the requirements in all of the three aforementioned areas. The qualitative characteristics of individual additive manufacturing methods (Table 1) [12] may be helpful for the initial evaluation.

Table 1. Qualitative characteristics of the selected additive manufacturing methods.

\begin{tabular}{ccc}
\hline & Technology \\
\hline Property & FDM & SLS \\
\hline Surface finish & 2 & 0 \\
Accuracy & 0 & 2 \\
Capability of multiple materials & 2 & 0 \\
Production rate & 0 & 4 \\
Technology cost & 4 & 0 \\
\hline & 4-best 0-worst \\
\hline
\end{tabular}

In the developed method (Figure 2), the first step is to evaluate the part in terms of its suitability for additive manufacturing in relation to other manufacturing methods. The parts, for which additive manufacturing is not justified, are eliminated since there are other manufacturing methods that are capable of producing them faster or in a less costly way. The next step is to select the AM method and material.

The selection of a method and material is described as a subprocess, in which we use the knowledge already gathered in the database or generate new knowledge by conducting research in three areas. These steps are listed in order of importance for medical equipment.

The first step is to determine whether the part is in contact with the human body and whether the material will meet the cytotoxicity requirements. To determine whether these requirements are met, it is proposed to test the cytotoxicity of samples according to ISO 10993-5: 2009 [13] and ISO/IEC 17025: 2005 [14] against the HaCaT keratinocyte line, L929 fibroblasts, and pulmonary alveoli lines A549. The test should be carried out in eight replications.

The second step is to determine whether the material must exhibit antibacterial properties. For this purpose, it is recommended to test it with standard microbiological techniques using quantitative inoculation, the crystal violet method, and the method based on the assessment of the metabolic activity of cells. It is proposed to assess the microbial colonisation capacity/potential antimicrobial activity in the standard Tryptic soya broth medium (System I) and artificial saliva (System II) for Pseudomonas aeruginosa, Staphylococcus aureus, and Clostridium difficile. The measurement should be performed $8 \mathrm{~h}$ after settlement.

The third stage is the requirement related to the strength properties of the incrementally processed material. As part of this criterion, attention should be paid to the possibility and impact of the selected sterilization methods on the properties of the product whether sterilization is necessary.

If the requirements in the above areas are met, in the last stage, the efficiency of the selected production method should be compared with the specific demand for a given product. In the event of a crisis, the selection of materials and methods must be carried out in accordance with the current availability of machines and materials.

In the next step, the part should be designed or redesigned using DfAM. A prototype or a series of parts should be verified by medical personnel. At this stage, you may need to iterate the process through design improvements. Positive verification enables the transition to the stage of designing the technological process for serial production. The resulting technological data are saved in the verified parts of the database in the AM Virtual 
Storage web application, which is specifically prepared for this purpose. The use of a web application enables the commencement of distributed production using the resources of entities registered on the platform.
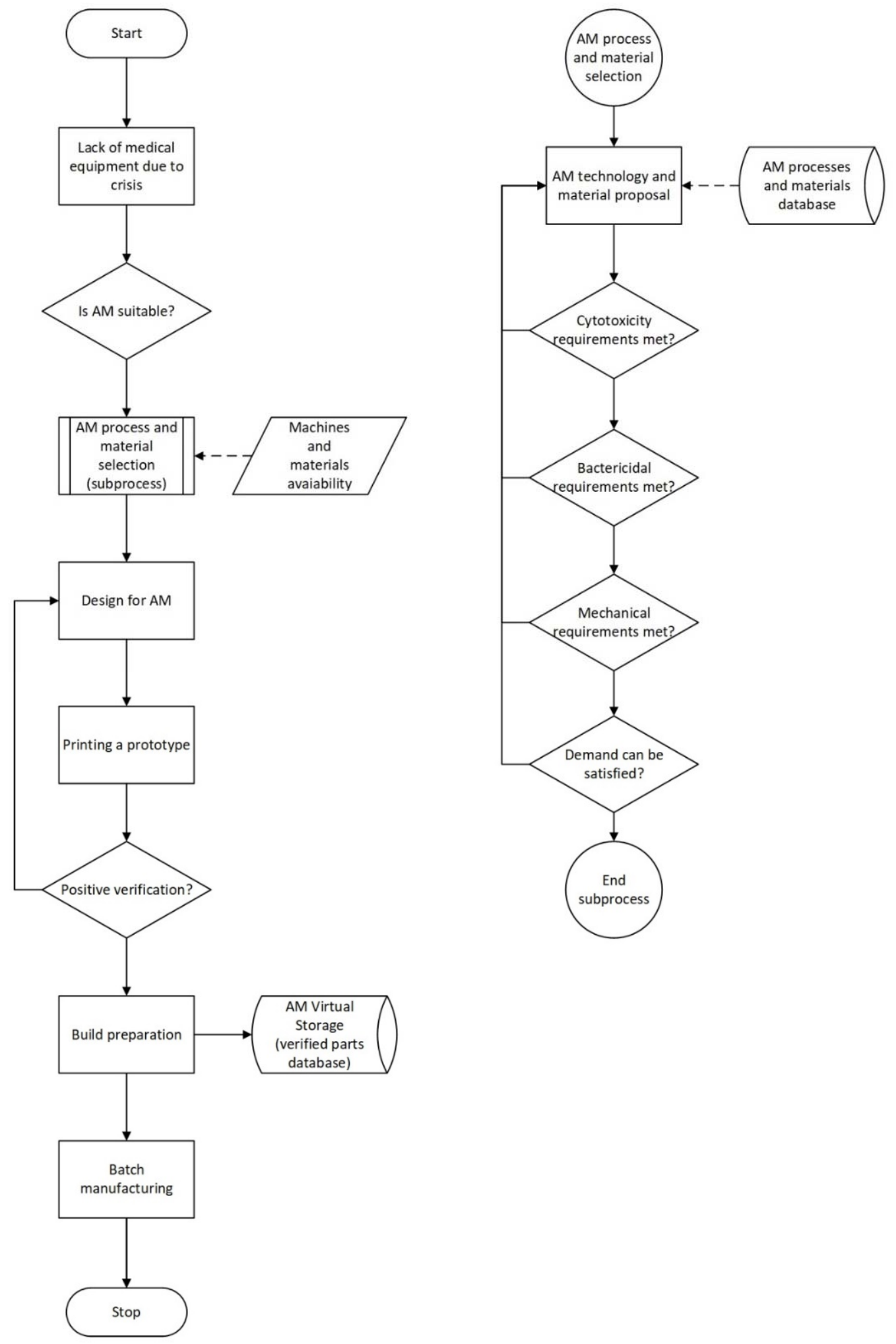

Figure 2. Procedure for the selection of a medical device/spare part for additive manufacturing. 


\section{Results and Discussion}

\subsection{Adapter Characteristics}

Using the described method, actions were taken in response to the lack of filters for full-face masks in the COVID-19 ward of the local medical facility. The goal was to deliver a prototype of an adapter within $24 \mathrm{~h}$ to connect the Honeywell North Pano CL3 mask to the widely available Covidien DAR filter (Figure 3), rather than the dedicated Honeywell 1788155 filter, whose availability was very limited at the time. The next stage was to deliver the adapters to all of the medical staff working in the ward within $72 \mathrm{~h}$ after prototype approval.

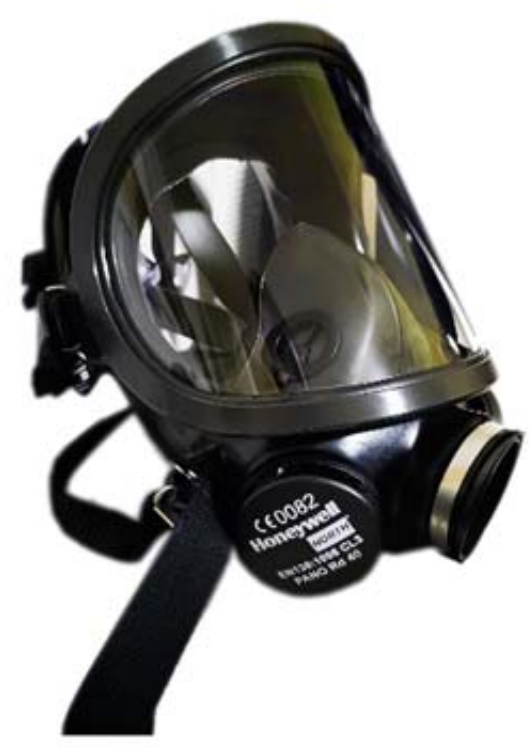

(a)

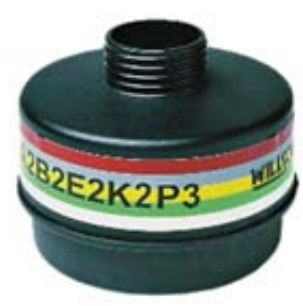

(b)

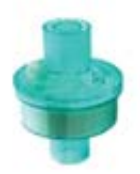

(c)

Figure 3. (a) Full-face mask; (b) dedicated filter for face mask; (c) DAR filter.

A secondary motivating factor for the use of the Covidien DAR filter was the medical staff complaints against the dedicated filter, including its considerable weight (395 g) and size limiting the view, all of which made the whole day's duty more strenuous. Of note, the weight of the Covidien DAR filter is $28 \mathrm{~g}$ and it does not obstruct the user's view due to its considerably smaller dimensions.

The characteristics of the product were determined on the basis of an interview conducted with a team of doctors. These are described in Table 2 (operational criteria). By the same token, the demand was determined at the level of 300 units.

Table 2. Usability requirements of the adapter.

\begin{tabular}{ccc}
\hline Area & Criteria & Requirements \\
\hline & ergonomics & low weight, easy to screw on, unlimited field of view \\
\cline { 2 - 3 } & functionality & $\begin{array}{c}\text { connection of the internal thread RD } 40 \text { of the full-face } \\
\text { mask with the filter outlet stub Ø22 mm push fit }\end{array}$ \\
\cline { 2 - 3 } Usability & sterilisation & yes \\
\cline { 2 - 3 } & cytotoxicity & non-cytotoxic \\
\cline { 2 - 3 } & rife cycle & $\begin{array}{c}\text { reusable, disposal in accordance with local regulations } \\
\text { for biohazardous waste }\end{array}$ \\
\cline { 2 - 3 } & antibacterial & yes \\
\hline
\end{tabular}




\subsection{Selection of Material and Technology}

After analysing the defined areas, criteria (Figure 1), and requirements (Table 2), it had transpired that the adapter meets the conditions for its production with the use of additive manufacturing. Therefore, the material and technology selection stage began. Regarding the economic and environmental criteria, the current availability and price of the materials were analysed. The choice of material that was used to produce the adapter was largely dependent on the availability of 3D printing devices in the laboratory. On this basis, the following technologies and materials were found to be available:

- FDM-poly (acrylonitrile-co-butadiene-co-styrene) ABS;

- $\quad$ SLS-polyamide PA12.

The results of biological tests carried out for the selected materials in the subsequent stages of the subprocess are presented below. In the FDM method, the ABS material was used in the form of a wire under the trade name ABS-M30 manufactured by Stratasys. In the SLS method, the samples were made of PA12 powder, available under the trade name PA2200 manufactured by EOS [15]. The materials were applied as delivered, with no pretreatment. In Figure 4, the results of the cytotoxicity tests of the materials are shown.

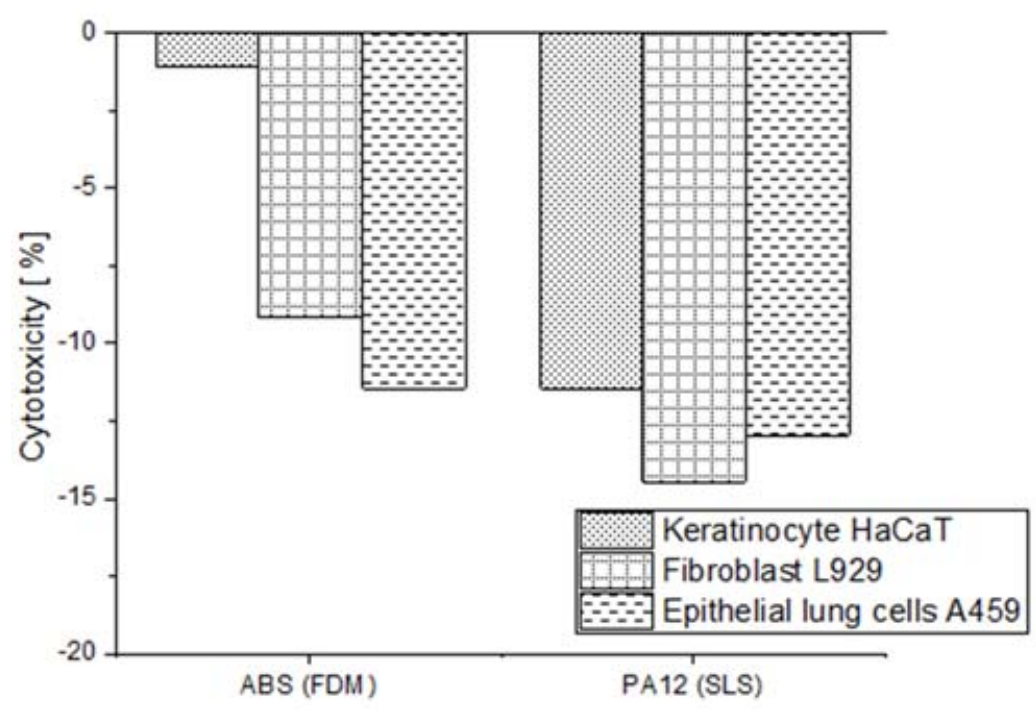

Figure 4. The determination of the cytotoxicity level of the samples tested against HaCaT, L929, and A549 cell lines.

Samples with a cytotoxicity below $30 \%$ are considered noncytotoxic, according to the standard. The "minus" sign next to the numerical value means that the extract from the incubation of the samples in the culture medium stimulated the test cells to grow beyond the cell growth level in the control system (untreated extract). The chart below shows that both the ABS material processed in the FDM and the PA12 material processed in the SLS are not cytotoxic for the tested cell lines. Of note, the PA12 material is characterised by a much lower level of cytotoxicity $(-11.5 \%)$ for Keratinocyte $\mathrm{HaCaT}$ compared to the ABS material $(-1.1 \%)$. Regarding the remaining cell lines, the PA12 material is also characterised by a lower level of cytotoxicity compared to the ABS material, but these differences are not very significant. For Fibroblast L929, the values are $-14.5 \%$ for PA12 and $-9.5 \%$ for ABS. For epithelial lung cells A459, which have the highest importance in this application, these values are $-13 \%$ for PA12 and $-11.5 \%$ for ABS, respectively.

The assessment of the surface colonisation capacity by the microorganisms/potential antimicrobial activity in the Tryptic soya broth (system I) and in the artificial saliva (system II) are presented in Figure 5a,b, respectively. The figure shows the $\%$ of the number of live cells on the surface of the test samples compared to the number of cells grown on the control surfaces in the test system. 


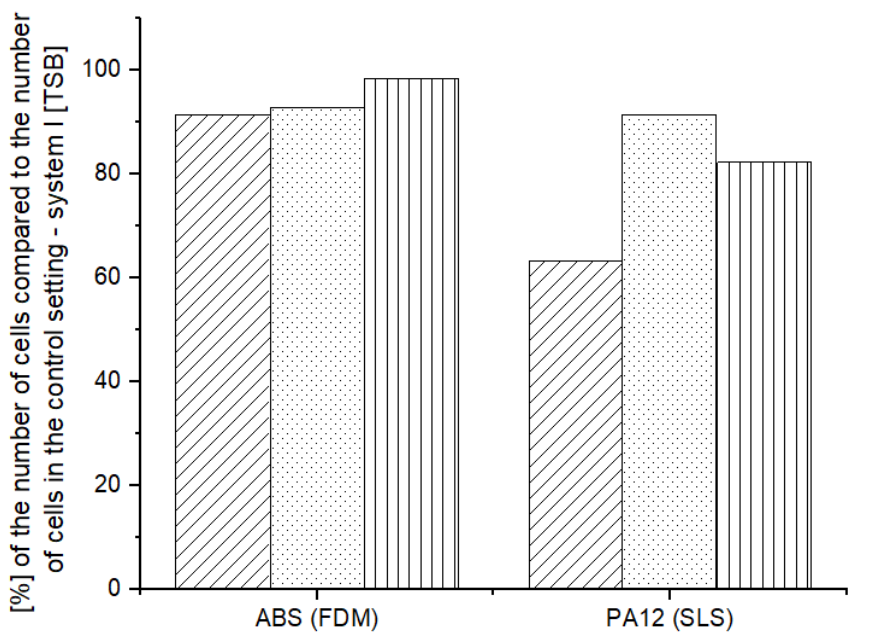

(a)

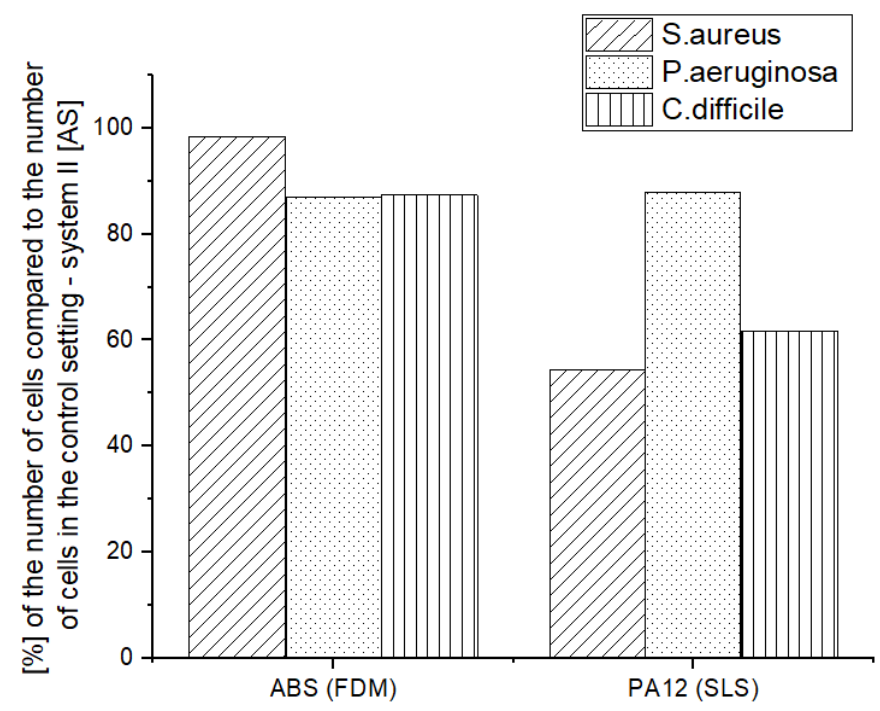

(b)

Figure 5. The assessment of the surface colonisation capacity by the microorganisms/potential antimicrobial activity: (a) Survival of bacteria on the ABS (FDM) and PA12 (SLS) substrate in the TSB microbiological medium; (b) survival of bacteria on the substrate made of ABS (FDM) and PA12 (SLS) in artificial saliva (AS).

The ABS for all of the analysed microbial strains shows low potential antimicrobial activity, both in the Tryptic soya broth (TSB) microbial medium and in artificial saliva (AS), as evidenced by the high percentage of the number of live cells on the surface of the tested samples compared to the number of cells grown on the control surfaces in research systems. For S. aureus, P. aeruginosa, and C. difficile, it was $98.4 \%, 93.1 \%, 91.5 \%$ in the Tryptic soya broth (TSB) microbial medium, and $98.5 \%, 87.2 \%, 87.4 \%$, respectively in artificial saliva.

On the other hand, the PA12 material was characterised by a much higher potential antimicrobial activity compared to ABS. The survival of the analysed strains of S. aureus, $P$. aeruginosa, and $C$. difficile was found to be at the level of $98.5 \%, 87.2 \%, 87.4 \%$ in the microbiological medium of Tryptic soya broth, and $54.4 \%, 88 \%, 61.7 \%$, respectively in artificial saliva.

The above studies have shown that the selected materials are characterised by low cytotoxicity, which is particularly important when the manufactured elements come into direct contact with humans. In this case, it cannot be concluded that the selected materials are antibacterial. In particular, the ABS material has very low potential antimicrobial activity. Regarding the PA12 material, this activity is noticeable for the S. aureus and C. difficile strains, while for the P. aeruginosa strain, this activity is at a level similar to ABS. This fully indicates the need to sterilize the adapters, which can be done with different techniques [16]. Sterilisation of ABS products produced with FDM technology can be performed with ethylene oxide (EtO) or Gamma radiation $[17,18]$. On the other hand, sterilization of PA12 products produced with SLS technology can be performed by the autoclave $\left(121^{\circ} \mathrm{C}\right)$ and ethylene oxide or steam formaldehyde at $60-80^{\circ} \mathrm{C}[16,17]$.

Taking into consideration that the adapters were manufactured using the process parameters recommended by the manufacturer of the material/device, it was assumed that the mechanical properties were in line with the material sheet. Furthermore, the mechanical properties of ABS material processed in FDM [19] and PA12 material [15] processed in SLS have been described in the literature [20,21].

The description of the mechanical properties contained in the above-mentioned material data sheets and articles leads to the conclusion that the above materials are suitable for the production of the adapter. The mechanical properties of PA12, however, are higher than those of ABS [15,19]. Furthermore, the products made of PA12 material after the SLS process are characterised by closed porosity at the level of about 5\% [20], while in the case 
of ABS products, after the FDM process, the products are characterised by open porosity. It is important, particularly in the case of the manufactured adapter, where it is necessary to maintain an air-tight connection with the mask filter.

Based on the conducted analysis (Table 3), previous research, and literature review, it was confirmed that it is possible to use FDM and SLS technologies to produce a prototype and small series for the medical industry.

Table 3. Evaluation of the suitability of selected materials and technologies for the production of a full-face mask filter adapter.

\begin{tabular}{|c|c|c|c|}
\hline \multirow[b]{2}{*}{ Area } & \multirow[b]{2}{*}{ Criteria } & \multicolumn{2}{|c|}{ Technology } \\
\hline & & ABS (FDM) & PA12 (SLS) \\
\hline \multirow{6}{*}{ Usability } & ergonomics & $\begin{array}{c}0 \\
\text { produces sharp edges }\end{array}$ & 4 \\
\hline & functionality & $\begin{array}{c}0 \\
\text { possible leaks }\end{array}$ & 4 \\
\hline & sterilisation & 0 & 4 \\
\hline & cytotoxicity & 0 & 4 \\
\hline & life cycle & 0 & 4 \\
\hline & antibacterial & 0 & 4 \\
\hline \multirow{4}{*}{$\begin{array}{l}\text { Economical and } \\
\text { environmental }\end{array}$} & price of the material & 0 & 4 \\
\hline & material availability & 4 & 4 \\
\hline & availability of machines & 4 & 0 \\
\hline & demand & 300 pcs & 300 pcs \\
\hline \multirow{4}{*}{ Manufacturing } & technology/DfAM & 0 & 4 \\
\hline & productivity & 0 & 4 \\
\hline & scalability & 4 & 0 \\
\hline & & \multicolumn{2}{|c|}{4 -best 0 -worst } \\
\hline
\end{tabular}

\subsection{Product Design with the Use of DfAM and Rapid Prototyping}

As indicated by the usability requirements, when designing the adapter geometry, it was necessary to take into account the geometric features of the full-face mask, the DAR filter, and the criteria presented in Table 2. After the measurements, it was found that the full-face mask has an internal thread RD 40 with a length of $20 \mathrm{~mm}$, while the DAR filter has an outlet with a diameter of $\varnothing 22 \mathrm{~mm}$ and a length of $15 \mathrm{~mm}$.

After receiving the mask and the DAR filter from the hospital, a prototype adapter was designed and manufactured. Despite the advantage of the SLS method in the described application, at the prototyping stage, individual pieces of the product are produced, therefore, for economic reasons, the FDM method was applied using the Stratasys F170 machine with GrabCAD Print software. Adapter prototypes were printed using a $\varnothing 0.33 \mathrm{~mm}$ nozzle and a layer height of $0.33 \mathrm{~mm}$. The filling density was set to $100 \%$. The correctness of the prototype was tested by mounting it to the supplied mask and filter, thus ensuring that the minimum operational requirements were met. The adapter prototype was delivered to the hospital $22 \mathrm{~h}$ after the need emerged (Figure 6).

After the adapter tests had been carried out, information was obtained that there were difficulties with screwing in/unscrewing the adapter from the mask. This indicates that the adapter cannot be fully screwed into the mask, which can in turn result in an increased distance between the mask and filter inlet (Figure 7).

To facilitate the screwing in/unscrewing of the adapter from the mask, it was decided to add gripping elements. Two design variants were proposed with two and eight grips, and two other designs with two and eight gripping tongues. After further tests, it was 
found that version 3 of the adapter is easier to screw in/unscrew. Sadly, the elements that facilitate the screwing in/unscrewing of the adapter in version 3 had sharp edges, which tore the disposable gloves. The sharp edges resulted directly from the limitation of the FDM technology and appeared at the point of contact of the model with the platform and at the seam.

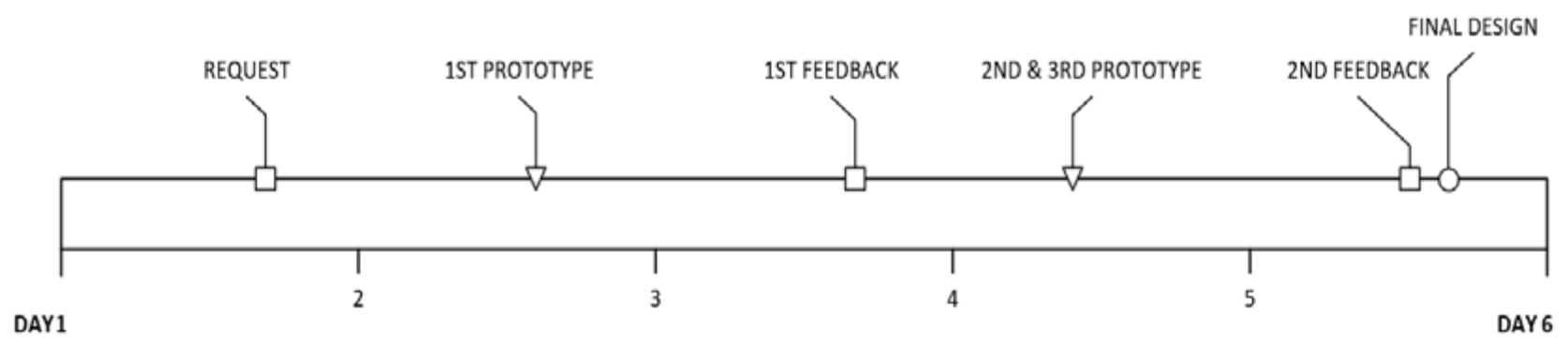

Figure 6. Timeline of the designing and prototyping process.

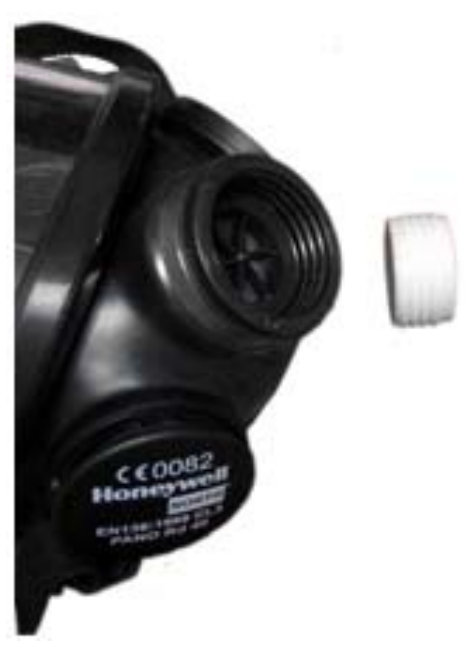

(a)

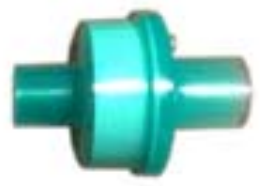

(b)

Figure 7. Face mask, mask filter adapter prototype (version no. 1), and DAR filter. (a) Before assembly; (b) after assembly.

The authors of [22] presented a whole range of different PPEs produced with the use of FDM technology to fight against COVID-19. Moreover, the authors of [23] presented a model of an adapter for the full-face snorkel mask, which was manufactured with the FDM technology. However, the above publications did not consider a systematic approach that takes into account risk inducing factors, such as material cytotoxicity and antimicrobial activity properties. Due to the limitations of FDM technology, the produced parts are more susceptible to leakage. This is an important factor in the protection against COVID-19. Therefore, the SLS technology was selected for the production of the batch of adapters, since this technology ensures that the manufactured elements will be solid and characterised by low porosity [20].

\subsection{Batch Production}

All of the comments from the hospital on the functionality of the prototypes were analysed, as shown above (Table 4). It was decided to introduce final modifications and start the production of a series of adapters in version 4 using the SLS technology. This technology was selected as the target production method corresponding to the indicated demand. The same approach can also produce air-tight elements and the problem of sharp edges is eliminated. 
Table 4. Comparison of the design versions of the adapter from the prototype to the finished product.

\begin{tabular}{|c|c|c|c|c|}
\hline \multirow{3}{*}{ Adapter feature } & \multicolumn{4}{|c|}{ Version } \\
\hline & & & & \\
\hline & Version 1 & Version 2 & Version 3 & Version 4 \\
\hline Part volume $\left[\mathrm{cm}^{3}\right]$ & 16.52 & 17.11 & 21.93 & 18.03 \\
\hline Weight $[\mathrm{g}]$ & 15.36 & 15.91 & 20.39 & 16.77 \\
\hline $\begin{array}{l}\text { Printing time net }[\mathrm{h}] @ \\
\text { no. of parts }\end{array}$ & $\begin{array}{c}00: 45 @ 1 \\
14: 55 @ 25\end{array}$ & $\begin{array}{c}00: 47 @ 1 \\
11: 55 @ 20\end{array}$ & $\begin{array}{c}01: 03 @ 1 \\
13: 45 @ 16\end{array}$ & 27:00@ 150 \\
\hline $\begin{array}{l}\text { Price per part } \\
\text { (comparatory) }\end{array}$ & $\$ \$ \$$ & $\$ \$ \$$ & $\$ \$ \$$ & $\$$ \\
\hline Comfort of usage & very low & low & moderate & high \\
\hline $\begin{array}{l}\text { Recommended number } \\
\text { of parts per process } \\
\text { [pcs] }\end{array}$ & 25 & 20 & 16 & 150 \\
\hline Material & ABS & ABS & ABS & PA12 \\
\hline Method & FDM & FDM & FDM & SLS \\
\hline Sterilisation & possible & possible & possible & possible \\
\hline Postprocess required & support dissolving & support dissolving & support dissolving & abrasive blasting \\
\hline $\begin{array}{l}\text { Part dimensions } \\
{[\mathrm{X} \times \mathrm{Y} \times \mathrm{Z} \mathrm{mm}]}\end{array}$ & $40.2 \times 40.2 \times 20.0$ & $45.3 \times 45.3 \times 20.0$ & $47.2 \times 47.2 \times 25.0$ & $47.9 \times 47.9 \times 20.0$ \\
\hline
\end{tabular}

The EOS Formiga P110 device and Magics 24.1 software (Materialize) were used. Since it was not possible to meet the demand in one construction process, due to the working area of the device, the products were made in two batches of 150 pieces each. With this number, the filling density of the working area was $16.39 \%$, which does not generate the risk of local heat accumulation (Figure 8).

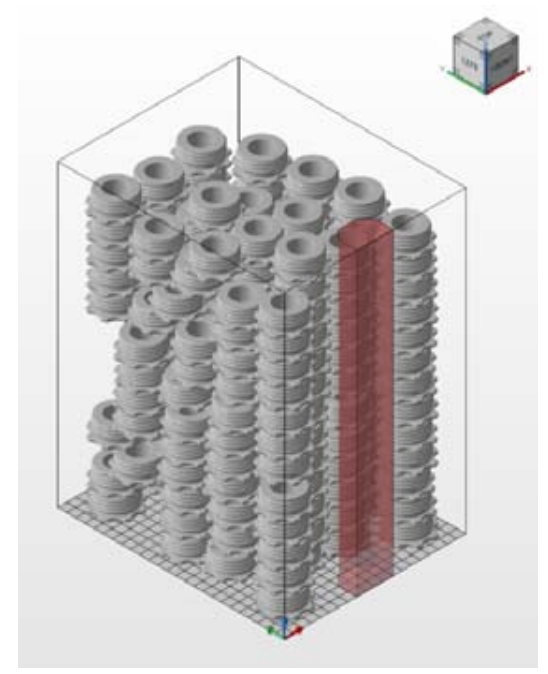

(a)

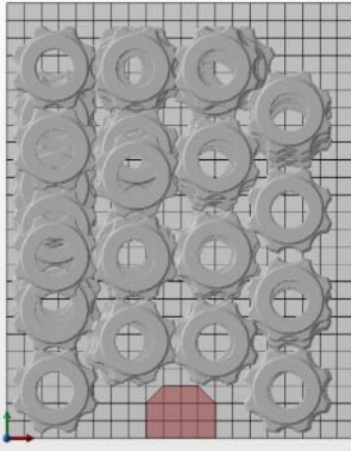

(b)

Figure 8. Three-dimensional model arrangements in the working space of SLS (Formiga P110): (a) Isometric view; (b) top view. 
The adapters were produced with a layer height of $0.1 \mathrm{~mm}$. The designed manufacturing technology included $27 \mathrm{~h}$ of build time and time related to preparatory and finishing activities, giving a total time of $55 \mathrm{~h}$ per batch (Figure 9).

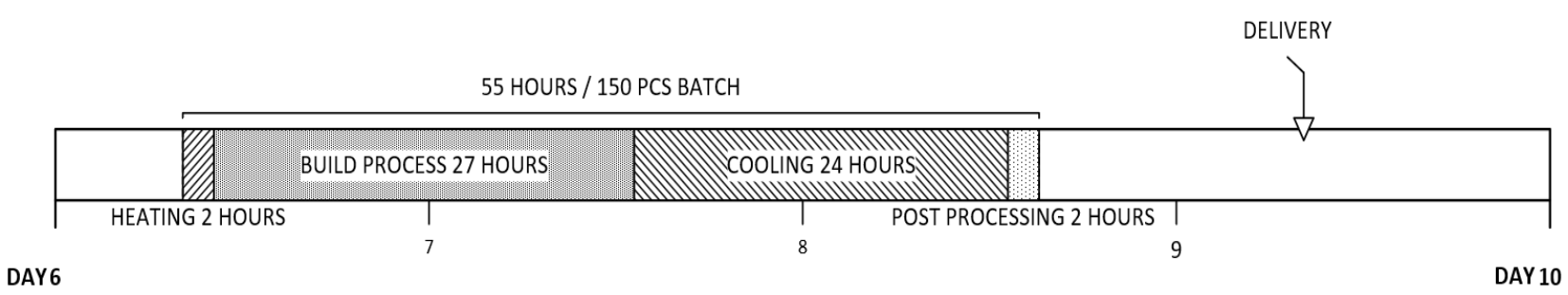

Figure 9. Timeline for the case study of producing a batch of 150 adapters in SLS technology.

The production of the second batch followed the same pattern, and started on the day following the completion of the delivery. The second production batch allowed hospital workers to have two adapters per mask. The final adapter, version 4 , is presented in Figure 10.

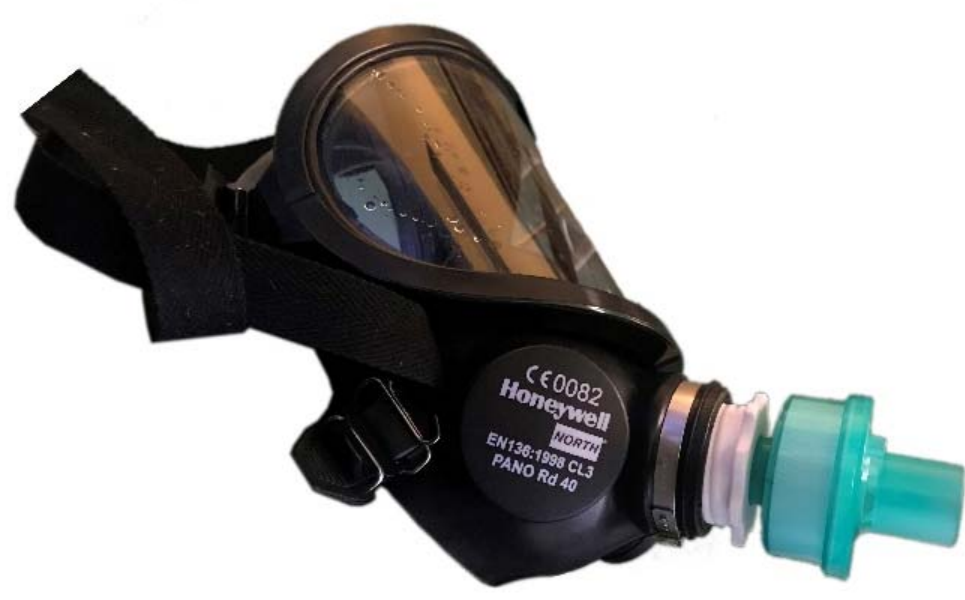

(a)

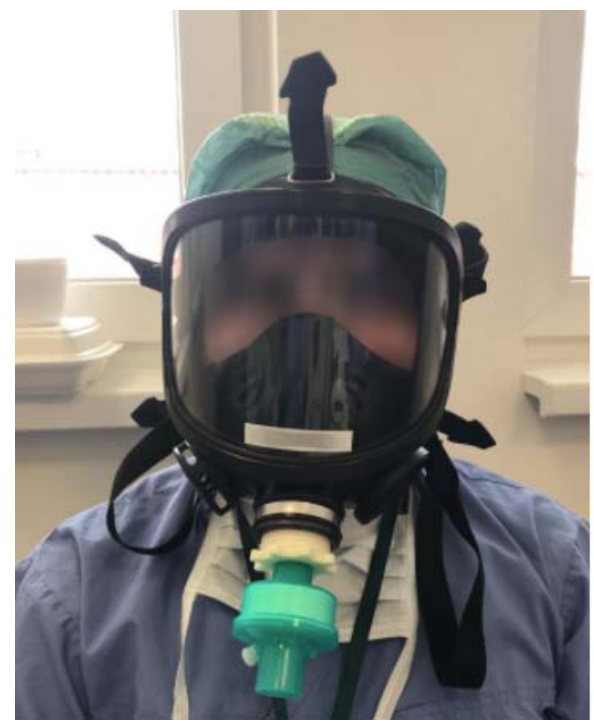

(b)

Figure 10. Face mask with the installed final version (no. 4) of the adapter and filter: (a) Final version of mask adapter; (b) example on the use of the mask with the adapter by medical personnel in a hospital.

\section{Conclusions}

This article describes the production of a fully functional full-face mask adapter. Additionally, it confirms the effectiveness of the procedure of the additive manufacturing method selection for producing medical consumables, spare parts or PPE. The proposed methodology offers the possibility of the immediate production of additive spare parts, alternative medical equipment, and personal protective equipment in a dispersed environment in crisis situations.

The described method contributed to the implementation of an internet platform, in which medical personnel can report, in emergency situations, the demand for the required equipment, that can be quickly produced with the use of $\mathrm{AM}$, using a distributed production environment.

The designed full-face mask filter adapter made a more efficient use of the available resources, in a crisis moment of shortage of dedicated filters, caused by the interrupted supply chain during the COVID-19 pandemic. 
Standard materials, such as ABS in FDM and PA12 in SLS, are not cytotoxic. They do not show significant antibacterial properties either, thus sterilisation is necessary.

The FDM technology has proven to be a perfect solution at the rapid prototyping stage of custom products used in healthcare. The drawbacks of this technology resulted in sharp edges of the product, which damaged disposable gloves. The economic aspect of manufacturing has yet to be considered. As for the case described above, the cost of FDM technology would be significantly higher than the cost of producing a series of 150 items by means of SLS technology.

In this paper, we speculate that the solution presented does not provide better protection than the dedicated mask filters. Still, in the event of a shortage of dedicated filters caused by interrupted supply chains, the presented solution can be applied to multiply the available number of masks. In the crisis caused by COVID-19, it ensured the continuity of healthcare provision.

The method presented in this paper was used to evaluate and prepare a mask filter adapter to be additionally manufactured in compliance with minimal medical requirements, which increased the number of available full-face masks in Poland's Specialist Hospitals during COVID-19 while the supply chains were broken.

Author Contributions: Conceptualisation, M.K. and G.K.; methodology, M.K.; software, G.K.; validation, M.K. and G.K.; formal analysis, M.K. and G.K.; writing-original draft preparation, M.K.; writing-review and editing, M.K. and G.K.; visualisation, G.K.; supervision, T.K.; project administration, T.K.; funding acquisition, T.K. All authors have read and agreed to the published version of the manuscript.

Funding: This research was funded by the National Center for Research and Development in Poland, grant number SZPITALEJEDNOIMIENNE/6/2020.

Acknowledgments: This research was performed thanks to the support of the National Center for Research and Development in Poland in the frame of project "On-the-spot additive production method of spare and alternative medical parts as well as personal protective equipment (PPE) in a dispersed environment in crises-Virtual AM Storage COVID-19", grant number SZPITALEJEDNOIMIENNE/6/2020.

Conflicts of Interest: The authors declare no conflict of interest.

\section{References}

1. WHO. Coronavirus Disease (COVID-19) Pandemic. Available online: https://www.who.int/emergencies/diseases/novelcoronavirus-2019 (accessed on 10 October 2021).

2. Li, Q.; Guan, X.; Wu, P.; Wang, X.; Zhou, L.; Tong, Y.; Ren, R.; Leung, K.S.M.; Lau, E.H.Y.; Wong, J.Y.; et al. Early Transmission Dynamics in Wuhan, China, of Novel Coronavirus-Infected Pneumonia. N. Engl. J. Med. 2020, 382, 1199-1207. [CrossRef] [PubMed]

3. Li, X.; Wang, W.; Zhao, X.; Zai, J.; Zhao, Q.; Li, Y.; Chaillon, A. Transmission dynamics and evolutionary history of 2019-nCoV. J. Med. Virol. 2020, 92, 501-511. [CrossRef]

4. N95 Respirators, Surgical Masks, Face Masks, and Barrier Face Coverings. Available online: https://www.fda.gov / medicaldevices / personal-protective-equipment-infection-control/n95-respirators-surgical-masks-face-masks-and-barrier-facecoverings (accessed on 15 October 2021).

5. Wesemann, C.; Pieralli, S.; Fretwurst, T.; Nold, J.; Nelson, K.; Schmelzeisen, R.; Hellwig, E.; Spies, B.C. 3-D Printed Protective Equipment during COVID-19 Pandemic. Materials 2020, 13, 1997. [CrossRef] [PubMed]

6. Patel, P.; Gohil, P. Role of additive manufacturing in medical application COVID-19 scenario: India case study. J. Manuf. Syst. 2021, 60, 811-822. [CrossRef] [PubMed]

7. COVID-19 Call to Action Stopgap Face Mask (SFM)-Instructions for Use. 2020. Available online: https://www.3dsystems.com/ covid-19-response (accessed on 7 September 2021).

8. Ford, J.; Goldstein, T.; Trahan, S.; Neuwirth, A.; Tatoris, K.; Decker, S. A 3D-printed nasopharyngeal swab for COVID-19 diagnostic testing. 3D Print. Med. 2020, 6, 1-7. [CrossRef] [PubMed]

9. Jiang, W.; Cao, W.; Liu, Q. Wearing the N95 mask with a plastic handle reduces pressure injury. J. Am. Acad. Dermatol. 2020, 82, 191-192. [CrossRef]

10. Ranney, M.L.; Griffeth, V.; Jha, A.K. Critical Supply Shortages-The Need for Ventilators and Personal Protective Equipment during the COVID-19 Pandemic. N. Engl. J. Med. 2020, 382, e41. [CrossRef] [PubMed] 
11. Wu, H.-L.; Huang, J.; Zhang, C.J.; He, Z.; Ming, W.-K. Facemask shortage and the novel coronavirus disease (COVID-19) outbreak: Reflections on public health measures. EClinicalMedicine 2020, 21, 100329. [CrossRef] [PubMed]

12. Abdulhameed, O.; Al-Ahmari, A.; Ameen, W.; Mian, S.H. Additive manufacturing: Challenges, trends, and applications. AIME 2019, 11, 1-27. [CrossRef]

13. Standard ISO 10993-5:2009 Biological Evaluation of Medical Devices-Part 5: Tests for in Vitro Cytotoxicity. Available online: https:/ / www.iso.org/standard/36406.html (accessed on 5 September 2021).

14. Standard ISO/IEC 17025:2005 General Requirements for the Competence of Testing and Calibration Laboratories. Available online: https:/ / www.iso.org/standard/39883.html (accessed on 5 September 2021).

15. Material Data Sheet PA2200/PA12. Available online: https://eos.materialdatacenter.com/eo/material/pdf/429809/PA220 0Balance1.0?sLg=en\&rnd=1638444905883 (accessed on 2 December 2021).

16. Tejo-Otero, A.; Buj-Corral, I.; Fenollosa-Artés, F. 3D Printing in Medicine for Preoperative Surgical Planning: A Review. Ann. Biomed. Eng. 2020, 48, 536-555. [CrossRef] [PubMed]

17. Linares-Alvelais, J.A.R.; Figueroa-Cavazos, J.O.; Chuck-Hernandez, C.; Siller, H.R.; Rodríguez, C.A.; Martínez-López, J.I. Hydrostatic High-Pressure Post-Processing of Specimens Fabricated by DLP, SLA, and FDM: An Alternative for the Sterilization of Polymer-Based Biomedical Devices. Materials 2018, 11, 2540. [CrossRef]

18. Perez, M.A.; Block, M.S.; Espalin, D.; Winker, R.; Hoppe, T.; Medina, F.; Wicker, R.B. Sterilization of FDM-manufactured parts. In Proceedings of the International Solid Freeform Fabrication Symposium, Austin, TX, USA, 6-8 August 2012.

19. FDM Thermoplastic Filament, ABS-M30 Product Data Sheet. Available online: https://www.stratasys.com/-/media/files/ material-spec-sheets/mds_fdm_abs-m30_0921a.pdf (accessed on 3 November 2021).

20. Olejarczyk, M.; Gruber, P.; Ziółkowski, G. Capabilities and Limitations of Using Desktop 3-D Printers in the Laser Sintering. Process Appl. Sci. 2020, 10, 6184. [CrossRef]

21. Popescu, D.; Zapciu, A.; Amza, C.; Baciu, F.; Marinescu, R. FDM process parameters influence over the mechanical properties of polymer specimens: A review. Polym. Test. 2018, 69, 157-166. [CrossRef]

22. Singh, S.N.; Venkatesh, V.S.S.; Deoghare, A.B. A review on the role of 3D printing in the fight against COVID-19: Safety and challenges. Rapid Prototyp. J. 2021, 27, 407-420. [CrossRef]

23. Nicholson, K.; Henke-Adams, A.; Henke, D.M.; Kravitz, A.V.; Gay, H.A. Modified Full-Face Snorkel Mask as COVID-19 Personal Protective Equipment: Quantitative Results. HardwareX 2021, 9, e00185. [CrossRef] [PubMed] 